\title{
POÉTICAS DA AUTORALIDADE NO CONTEXTO DA EXTENSÃO UNIVERSITÁRIA
}

\section{Poetics of Authorship in the Context of University Extension}

\author{
Anamaria Fernandes Viana \\ Mônica Maria Farid Rahme \\ Universidade Federal de Minas Gerais - UFMG
}

Resumo: Este artigo apresenta dados relativos a um projeto de extensão desenvolvido na Universidade Federal de Minas Gerais (Campus Belo Horizonte) com jovens e adultos em situação de deficiência, desde 2017. O trabalho consiste na oferta de oficinas artísticas, abertas à comunidade interna e externa à Universidade, e desenvolvidas por estudantes de diferentes cursos de graduação. No texto, discutimos os princípios que orientam essa experiência, relacionando-os a depoimentos de participantes. O projeto busca investigar uma poética da autoralidade que permita a expressão e 0 acolhimento de múltiplas manifestações dos sujeitos.

Palavras-chave: Arte; Deficiência; Extensão Universitária.

Abstract: This article presents data concerning an extension project developed at the Federal University of Minas Gerais (Belo Horizonte Campus) with young people and adults with disabilities, since 2017. The work consists of offering artistic workshops developed by students from different undergraduate courses to the internal and external community of the University. In the text, we discuss the principles that guide this experience, relating them to testimonials of participants. The project seeks to investigate a poetics of authorship that allows the expression and acceptance of multiple manifestations of the subjects.

Keywords: Art; Disability; University Extension. 
Este artigo tem como objetivo apresentar e discutir dados referentes ao trabalho que desenvolvemos, no contexto universitário, com um grupo composto por estudantes de diferentes cursos de graduação, jovens e adultos em situação de deficiência e acompanhantes. Trata-se do Projeto Arte e Diferença, que realiza, desde 2017, oficinas artísticas abertas à comunidade interna e externa à Universidade Federal de Minas Gerais (UFMG). As oficinas acontecem uma vez por semana e pretendem fomentar a realização de contatos mistos (GOFFMAN, 1988) entre pessoas que experimentam a questão da deficiência e pessoas que se interessam pela proposta sem necessariamente estar em situação de deficiência.

Para contextualizar o projeto Arte e Diferença, iniciamos o texto abordando o processo de reconhecimento e ampliação dos direitos das pessoas em situação de deficiência no Brasil. Em seguida, apresentamos dados referentes às iniciativas de nossa universidade em relação à temática da deficiência; para, em um terceiro momento, discutir pontos específicos do projeto.

\section{Pessoas em situação de deficiência e cidadania no Brasil}

As conquistas referentes aos direitos das pessoas em situação de deficiência no Brasil são resultantes de movimentos políticos que se fortalecem a partir dos anos de 1970 e que aproximaram diferentes associações em torno do estabelecimento de uma pauta reivindicatória comum nos anos de 1980. Após 21 anos de ditadura militar, essa grande mobilização tinha como foco a inserção dos direitos das pessoas em situação de deficiência nos capítulos da Constituição Federal de 1988, juntamente aos demais segmentos da população, e não como um capítulo à parte (MAIOR, 2017).

A Constituição Federal de 1988, conhecida como constituição cidadã, marca um pacto federativo no processo de democratização do país, afirmando a igualdade de todos perante a Lei e situando a educação, a saúde, a assistência social, a moradia, como direitos de todos. Embora esse acontecimento histórico não minimize os desafios sociais, econômicos e políticos enfrentados pelo país no 
passado e no presente, evidenciou, naquele momento, a emergência e o fortalecimento pulsante de inúmeros grupos sociais (SADER, 1988), como o movimento político das pessoas com deficiência.

Para compreender a relevância desse momento, é importante observar que em grande parte do século XX, poucas eram as políticas públicas específicas destinadas a esse público no Brasil. No campo da saúde, Centros de reabilitação, mantidos por organizações não governamentais, são criados nos anos de 1950, em decorrência de uma epidemia de poliomielite (MAIOR, 2017). Na área da educação, é visível a presença de uma expansão da escolarização das pessoas em situação de deficiência a partir dos anos 1950, o que decorre, de um lado, da criação de escolas especiais públicas e da abertura de classes especiais em alguns estados, como Minas Gerais (BORGES; CAMPOS, 2018); de outro, em decorrência de uma grande ampliação de instituições educativas especializadas, vinculadas a organismos assistenciais, mas que funcionavam, basicamente, com recursos públicos (KASSAR, 2013). É importante observar, ainda, que nessa época, várias ações governamentais ficavam sob responsabilidade da Legião Brasileira de Assistência (LBA) (MAIOR, 2017), que financiava o funcionamento de clínicas-escola no país. Essas clínicas, que por vezes ofereciam escolarização, atendiam crianças e adolescentes que apresentavam questões bastante heterogêneas, como dificuldades de aprendizagem, limitações motoras, particularidades psíquicas, dentre outras ${ }^{1}$.

Com a organização do movimento político das pessoas em situação de deficiência nos anos de 1970 e 1980, somada ao processo de democratização do país, temos em 1986 a Criação da Coordenadoria Nacional para Integração da Pessoa Portadora de Deficiência (Corde) ${ }^{2}$, responsável pela Política Nacional para Integração da Pessoa Portadora de Deficiência, e em 1999, a constituição do Conselho Nacional dos Direitos da Pessoa com Deficiência (Conade). Temos,

\footnotetext{
${ }^{1}$ A LBA, criada pelo governo brasileiro em 1942, com a finalidade de apoiar as famílias dos soldados enviados para a II Guerra Mundial, passou a assumir uma série de atribuições nas décadas seguintes, dentre elas, a assistência às pessoas em situação de deficiência. No início de 1995, a LBA é extinta, sendo alvo de críticas pelo caráter assistencialista de suas ações e pela sua pouca expressividade no cenário nacional.

${ }^{2}$ Em 2009, a Coordenadoria é transformada em Secretaria Nacional de Promoção dos Direitos da Pessoa com Deficiência.
} 
ainda, no final dos anos de 1980, a promulgação da primeira legislação federal endereçada às pessoas em situação de deficiência, a Lei 7.853/1989, que dispõe, dentre outros aspectos, sobre o apoio a esse público, sobre a tutela jurisdicional de seus interesses coletivos ou difusos e sua integração social. Nesse período, o Brasil incorpora em várias de suas orientações políticas a perspectiva da integração social e educativa, embora a responsabilização do estado por essas ações e pela oferta de atendimento a esse público só passe a se concretizar efetivamente após a promulgação da Constituição de 1988.

Posteriormente, nos anos de 1990, a partir da circulação de um conjunto de documentos internacionais ${ }^{3}$ voltados para o reconhecimento das particularidades dos diferentes grupos que compõem a sociedade, sua autonomia e relevância para o coletivo, verificamos mudanças significativas na legislação brasileira, bem como uma maior ampliação da oferta de serviços a essa população. No plano legislativo, podemos citar a aprovação de leis relacionadas ao acesso ao mercado de trabalho (1990-1991); ao atendimento educacional especializado (1996); à acessibilidade física e comunicacional (2000; 2004), ao reconhecimento da Língua brasileira de sinais (2002). No plano dos atendimentos, com a emergência da proposição de uma educação inclusiva, constatamos o início de uma maior abertura à escolarização dos estudantes em situação de deficiência nas escolas comuns. No campo da saúde, o Sistema Único de Saúde (SUS) passa a desenvolver, paulatinamente, ações que consideram as necessidades específicas dessa população. Um outro dado importante é que, a partir de 2006, são realizadas Conferências dos Direitos da Pessoa com Deficiência, que reúnem ativistas, técnicos e familiares envolvidos com inclusão social.

Quase três décadas após a promulgação da Constituição Federal de 1988, temos em 2015 a aprovação da Lei Brasileira de Inclusão (LBI) - Estatuto da Pessoa com Deficiência, que reafirma direitos fundamentais dessa população,

\footnotetext{
3 Referimo-nos à Déclaration mondiale de l'éducation pour tous (Unesco, 1990); Déclaration de Salamanque: Sobre Princípios, Políticas e Práticas na Área das Necessidades Educativas. Especiais (Unesco, 1994); Convenção Interamericana para a Eliminação de Todas as Formas de Discriminação contra as Pessoas Portadoras de Deficiência - Convention du Guatemala (1999); Convention sobre os direitos das pessoas com deficiência (2006).
} 
como o direito à vida e à reabilitação, à saúde, à educação, à moradia e ao trabalho, e orienta o estado brasileiro no seu cumprimento. Embora a afirmação desses direitos estivesse contemplada em um conjunto de legislações anteriores, a LBI reafirma essas proposições, e se torna ainda mais relevante quando, a partir do ano de 2016, após o golpe que destituiu a presidenta eleita Dilma Rousseff, o governo passa a adotar um conjunto de medidas que tendem a reduzir o investimento público em políticas que refletem a afirmação de direitos fundamentais.

Após esse breve panorama referente à realidade brasileira e à conquista de direitos por parte da população em situação de deficiência nas últimas décadas, abordaremos, de modo suscinto, questões referentes à nossa universidade, que possibilitem situar o Projeto Arte e Diferença nesse contexto.

\section{A UFMG e a temática da deficiência}

A universidade tem como eixos fundamentais e indissociáveis o ensino, a pesquisa e a extensão, dimensão à qual se articula o nosso projeto. A extensão universitária busca integrar o ensino e a pesquisa, fomentando ações que aproximem o conhecimento produzido no âmbito universitário aos diferentes setores da população e estimulando a participação social. Pretende, ainda, tornar as ações extensionistas material profícuo para o ensino e a pesquisa, dada a sua riqueza e vivacidade. Por isso, as ações de extensão constituem-se como uma modalidade relevante para refletir sobre o currículo e sobre as práticas formativas desenvolvidas nos cursos de graduação (MEC, 2006), pois permitem relacionar os saberes acadêmicos aos diferentes contextos sociais, e possibilitam que os estudantes ajam, de modo reflexivo, em múltiplas realidades.

Ao propor as oficinas artísticas como ação de extensão universitária dentro da Universidade, o projeto Arte e Diferença busca estimular a participação da sociedade no espaço físico acadêmico, em especial das pessoas em situação de deficiência; criando situações nas quais os estudantes possam construir planejamentos de trabalho e intervir em situações concretas; promovendo 
espaços de análise das práticas desenvolvidas e de estudo, como focalizaremos mais detidamente no próximo item.

Ao lado das ações de extensão, a UFMG implementa a Lei de cotas, publicada em 2016, e que amplia a reserva de vagas para pessoas em situação de deficiência nas instituições federais de ensino (IFEs) (PETTEN, ROCHA; BORGES, 2018). A legislação anterior, datada de 2012, previa a reserva de $50 \%$ das vagas das vagas das IFEs para a população negra, parda e indígena. No Brasil, as IFEs são, em geral, consideradas instituições de excelência, tendo um número de demanda bastante superior ao número de vagas disponíveis.

Embora alguns cursos de graduação tenham em seus currículos disciplinas que abordam a temática da deficiência, a universidade passou a realizar em 2018 uma Formação Transversal em Acessibilidade e Inclusão, que possibilita aos alunos do bacharelado e da licenciatura um contato mais aprofundado com a temática da deficiência e da inclusão escolar. Os estudantes podem cursar toda a formação, que tem uma carga horária de 360 horas, ou disciplinas específicas, como complementação curricular (UFMG, 2019). Além de propiciar uma maior visibilidade à temática da deficiência na universidade, essa formação evidenciou os múltiplos olhares e perspectivas de investigação do tema.

Por fim, é importante observar que a UFMG possui um Núcleo de Acessibilidade e Inclusão (NAI), responsável por apoiar e acompanhar os estudantes em situação de deficiência nela matriculados. O Núcleo também financia projetos de pesquisa e extensão que favoreçam o estudo de temáticas relacionadas à deficiência, bem como a inclusão das pessoas em situação de deficiência. O Projeto Arte e Diferença vincula-se ao NAl em duas dimensões, integrando as ações de extensão financiadas pelo Núcleo e acolhendo estudantes em situação de deficiência por ele acompanhados.

A partir dos pontos levantados acima, passaremos a abordar mais diretamente o Projeto, seus desdobramentos, avanços e desafios potenciais. 


\section{O projeto de extensão Arte e Diferença}

O Arte e Diferença propõe, desde 2017, atividades artísticas gratuitas de Dança, Música e Teatro, ministradas por estudantes bolsistas selecionados pelo projeto PIPA do NAI/UFMG. As oficinas são abertas às pessoas com e sem necessidades especiais, pertencentes ou não à Universidade. A divulgação é feita por meio de redes sociais, cartazes e contatos estabelecidos com instituições de acolhimento para pessoas em situação de deficiência na cidade de Belo Horizonte.

Desde 2017, o projeto teve a participação de 12 (doze) estudantes, sendo 7(sete) bolsistas e 5 (cinco) voluntários. Uma monografia de Trabalho de Conclusão de Curso foi escrita por uma das bolsistas sobre o projeto. A cada ano, proporcionamos aos bolsistas e voluntários, oficinas artísticas preparatórias que visam desenvolver a construção de repertório para a realização das atividades. Encontros regulares de supervisão são feitos entre os bolsistas e as professoras coordenadoras do projeto e, quando necessário, são propostos novos encontros artísticos que visam aprofundar o conhecimento dos estudantes.

As oficinas acontecem durante todo o ano, uma vez por semana, na parte da manhã, no espaço do Teatro Universitário. As oficinas também foram oferecidas no ano de 2017 para crianças com e sem deficiência, no grupo de trabalho diferenciado (GTD), formado por crianças estudantes do Centro Pedagógico da UFMG.

Após a realização de cada oficina, o grupo se reúne para avaliação do trabalho efetuado e preparação do próximo encontro.

O projeto conta de maneira mais regular com a presença de jovens com autismo e suas acompanhantes (cuidadora e amiga), duas mulheres cadeirantes e outros estudantes da UFMG, que não se encontram em situação de deficiência. A presença e participação sensível da estudante universitária em situação de deficiência abriu novas perspectivas e discussões no projeto no que tange à acessibilidade, inclusão e ofertas de atividades para os próprios estudantes da instituição. 
Desde o início do projeto, acolhemos diferentes instituições da cidade que trabalham com pessoas em situação de deficiência. Dentre elas, destaca-se o Programa Mala Lúdica, da Prefeitura de Belo Horizonte, que, desde 2018 participa do projeto trazendo grupos de pessoas em situação de deficiência, familiares e profissionais.

Desde o início, o projeto acolhe estudantes de diferentes graduações que cursam a disciplina Dança e Necessidades Especiais, disciplina essa que faz parte da Formação Transversal em Acessibilidade e Inclusão. Pelos diferentes relatos dos estudantes, nota-se que esta experiência tem-se mostrado extremamente importante na formação dos graduandos. A partir de 2019, o projeto passa a receber estudantes do curso de Especialização em Transtornos do Espectro do Autismo da UFMG.

Tendo como referência a construção de uma sociedade mais democrática, na qual exista respeito, acolhimento e reconhecimento das diferenças - o que se constitui como um dos objetivos de uma educação inclusiva (UNESCO, 1994) criamos, no final de 2017, o Grupo de Estudos Corpos Mistos que visa introduzir os alunos das licenciaturas e do bacharelado, assim como pessoas da comunidade externa à universidade, nos estudos sobre deficiência, educação especial, inclusão escolar, arte, pesquisa, diversidade, proporcionando um espaço de discussão e aprofundamento teórico.

Desde 2017, o projeto realiza eventos sobre o tema Arte, Educação e Diferença, abertos à comunidade interna e externa à universidade.

\section{Princípios orientadores do projeto Arte e Diferença}

Alguns princípios têm se revelado fundamentais para delinear os pertencimentos teórico-conceituais do projeto, para a estruturação das ações que são propostas e para o estabelecimento de um trabalho coletivo que envolva a dimensão autoral dos estudantes da graduação, dos usuários e dos acompanhantes que participam ativamente dos encontros. Neste item, iremos 
abordar esses princípios, entrelaçando-os a depoimentos sobre o projeto, expressos por quatro estudantes bolsistas, uma usuária e uma acompanhante ${ }^{4}$.

Inicialmente, é importante dizer que o projeto não tem o objetivo de ministrar aulas artísticas, ensinar técnicas precisas, por isso a escolha do termo oficina. Os estudantes responsáveis pelas oficinas não são professores, mas condutores, ou, emprestando as palavras de Toledo (2007, p. 22), ao citar a obra de Fernand Deligny, eles são "criadores de circunstâncias", prontos a colher o desconhecido, de onde nascem novas configurações. Pensamos nas oficinas como encontros de partilha de uma experiência artística na qual cada um aprende com o outro a partir de "nossos próprios limites e possibilidades", como diria Fux (2011, p. 14). Para a estudante A.C.C, bolsista do Arte e Diferença "o projeto preza de forma intensa os momentos de encontro, seja com pessoas em situação de deficiência ou não, e são esses encontros que permitem a criação de diálogos artísticos e coletivos". O espaço das oficinas é composto por tentativas, termo também utilizado por Deligny, e que reflete uma maneira de trabalhar, de agir, uma forma de presença ativa no silêncio e que dá espaço ao imprevisto, à bricolagem, ao equilíbrio efêmero:

Uma tentativa não é uma instituição, mas um pequeno conjunto, uma pequena e flexível rede que se trama na realidade como ela é, nas circunstâncias como elas são, indo até mesmo ao encontro de situações que não podem ser criadas de forma arbitrária (DELIGNY, 2007, p. 691)

Uma das principais referências estruturais do projeto é a interdisciplinaridade. Desde o início, trabalhamos com estudantes da Dança, do Teatro, da Música, das Artes Plásticas, da Pedagogia, da Psicologia e da Terapia Ocupacional. Para nós, esta proposta de desfragmentação do saber permite a construção do conhecimento de forma circular, unificando diferentes abordagens de forma sensível e singular. O desenvolvimento da experiência artística pela

\footnotetext{
${ }^{4}$ Esses depoimentos foram extraídos de registros escritos pelos participantes do projeto Arte e Diferença no primeiro semestre de 2019 e serão citados ao longo do capítulo.

${ }^{5}$ Os textos originalmente escritos em língua estrangeira têm tradução nossa.
} 
prática interdisciplinar, vem se revelando como um espaço fecundo para revelações de poéticas individuais dentro do coletivo.

Como relata A.G., estudante bolsista do Arte e Diferença em 2017, "A interdisciplinaridade do projeto cativa outros caminhos. Novas possibilidades surgem e estas se conectam com a improvisação, dando margem para a criação de uma forma nunca vista em projetos que fomentam o cuidado especial".

A ludicidade é uma segunda referência do projeto, que tem por objetivo potencializar espaços de criação das propostas artísticas, de expressão, de construção de conhecimento e de relações sociais por meio de brincadeiras, muitas vezes construídas a partir de propostas apresentadas pelos próprios participantes. Essas brincadeiras que acolhem as singularidades existentes, levam em consideração os impulsos criativos, desejos, necessidades e especificidades de cada um, incentivando a imaginação, a iniciativa e a autonomia. A.G. conta que se sentiu "num jardim de infância", o que era, para ele, um "novo caminho de descobertas".

A autoralidade é um outro aspecto que valorizamos no trabalho. Para nós, quando a arte dá espaço à autoralidade da pessoa e revela sua sensibilidade, sua linguagem, sua criação singular, ela se faz território de transformação, não só para o indivíduo mas para o meio no qual ele está inserido. Como campo de diversidade, na celebração do comum e o do único, do coletivo e do individual, ela se torna um espaço político. Como relata D.M., acompanhante dos jovens com autismo, "temos um espaço de arte em que as sensações são cuidadosamente colhidas, distribuídas e valorizadas. Os participantes são também os autores, pois o respeito e o valor de cada prática interna é que faz as oficinas acontecerem." A.C.C., fala que este trabalho se funda "na observação voltada para o que os participantes trazem de encontro com a Arte."

Assim, longe das práticas que reduzem o indivíduo a uma deficiência, apostamos naquelas que provocam um desafio: o de se deixar-se surpreender e ensinar pelo saber do outro; o de compor a partir das invenções e potencialidades próprias de cada sujeito. E é a partir desta concepção de arte que sustentamos sua importância na sociedade, uma arte não normativa, despojada de regras e 
códigos hierárquicos, distante da visão do corpo como um objeto, instrumento de manipulação, de adestramento e submissões.

A autoralidade implica, também, a experiência que oferece o com ao invés do para, e que é tecida pela vulnerabilidade do encontro, por uma estrutura de incertezas e descobertas. Ela abarca a auto-poética do indivíduo. Ela proporciona a possibilidade concreta de uma transformação social e uma paisagem criadora que desvenda uma parte do seu próprio invisível que the era estrangeira. Invisível, aqui, nos dois sentidos de que nos fala Merleau-Ponty (1964): não somente o que não me é dado em função da posição em que me encontro e que passa a ser visível se eu mudar de posição espacial, mas o que habita no interior das coisas, no interior do mundo.

A acessibilidade é um quarto princípio fundamental do projeto. Apesar do crescente debate em torno da acessibilidade, raras são as propostas de atividades artísticas acessíveis. As pessoas em situação de deficiência ainda sofrem com o preconceito de serem consideradas incapazes, e muitos profissionais não têm interesse em atender este público. Freqüentemente, são vítimas de condutas que não consideram as relações muitas vezes peculiares que estas pessoas têm com seu próprio corpo, com o tempo, o espaço, a linguagem, o outro. Impomos um certo "saber", uma maneira de agir, de estar no mundo, privando a pessoa de ensinar e, ao mesmo tempo, privando-se de novas possibilidades, já que "existe inteligência lá onde cada pessoa age." (RANCIĖRE, 1987, p. 56).

Para nós, a preocupação com a acessibilidade nos faz construir novos fazeres a partir da diversidade de corpos, o que enriquece nosso saber. Ao mesmo tempo, perceber e acolher as singularidades dos indivíduos ali presentes, nos permite perceber e acolher a nossa própria singularidade, nossas próprias fragilidades. Pois é considerando cada pessoa como única e exemplar na sua multiplicidade evolutiva que, como nos diz Klein, "nos reconhecemos como semelhantes e como diferentes, e não em um genérico que nos ignora e nos uniformiza." (KLEIN, 2003, p. 384). É uma maneira de nos conectarmos com a nossa própria humanidade, com a humanidade em si, e com o outro; um modo de 
ver que, para além de sintomas que etiquetam o indivíduo, somos semelhantes em nossas diferenças. Neste sentido, D.M. (acompanhante) alega que os educadores e educadoras das oficinas "estão construindo seus métodos, suas técnicas e didáticas a partir da observação, conhecimento e relação com o que há de mais importante que é o ser humano. O ser humano com suas dificuldades, suas dúvidas, suas potências, sua diversidade".

A articulação entre o singular e o coletivo é também um princípio que prezamos pois, a cada oficina, buscamos celebrar a singularidade de cada um e, ao mesmo tempo, construir e produzir um espaço compartilhado. A questão da construção de um espaço comum em meio a singularidades tão distintas é um desafio e fonte de aprendizagem. Como diz ainda D.M.:

(...) a cada oficina o fazer é novo, singular e único. Se a arte é a singularidade, exercitamos a diferença e criamos novos caminhos. O que vivenciamos nas oficinas é arte como contemplação, como ação, reflexão, criação e respeito. (...) Aproximamos da diferença por meio da própria diferença...

Essa experiência dá nascimento a uma nova estética, uma estética do instante, do efêmero e que rompe com a dicotomia do "Nós" e "Outros". Ela torna possível a criação de um espaço comum, um espaço do "Nós", composto por cada singularidade, que tem ali o seu lugar, sua legitimidade de existência, sua importância vital. E para que o fazer artístico singular do sujeito possa abrir novas perspectivas de criação e diálogos artísticos, não basta simplesmente "tolerar" suas diferenças, mas olhar para elas com carinho, com disponibilidade, com curiosidade. A curiosidade da diferença do outro. Curiosidade sem a qual não construo, não crio, mas coloco, imponho, decreto. Freire (2005, p. 52) nos ensina que "O exercício da curiosidade convoca a imaginação, a intuição, as emoções, a capacidade de conjecturar, de comparar, na busca da perfilização do objeto ou do achado de sua razão de ser."

De fato, com muita tolerância, podemos corrigir os comportamentos desviantes, construir um projeto para a pessoa, sufocando sua subjetividade. $E$ isso, com uma imensa boa vontade. Se, dentro de cada um de nós, esse 
movimento não percorre um caminho, se ele não atravessa nossos poros e sentidos, se não nos afeta, não produzimos nenhuma poética a partir e com o outro, nenhuma forma de linguagem, de contato, de diálogo. Assim, devemos nos deixar levar pelo encantamento da diferença. E esse encantamento não se compra nem se vende: é tributário da veracidade de uma relação e, mais uma vez, de nossa capacidade em lidar com a diferença.

O projeto Arte e Diferença é, também, um espaço de desapego de expectativas, da vontade irrestrita do fazer, de resultados. Neste território ético, percebemos a intensidade de nossas próprias projeções, do nosso ego, da nossa necessidade de conquista. Desejamos, muitas vezes, pelo outro, no lugar do outro. É evidente que nossos desejos são motores de nossas ações, mas para nós, é primordial manter uma vigilância constante entre a distância que existe entre um desejo que se faz "vontade cega" e um desejo poroso, capaz de calar os impulsos do eu, para se deixar penetrar pelo desejo do outro. Para tal, procuramos experimentar e explorar os territórios criativos próprios de cada participante, por meio de propostas que se dão sob forma de convites. Este também é um outro princípio chave do projeto: convites que têm por objetivo incitar, provocar um desejo, não um desejo orientado, com um objetivo préestabelecido, mas um desejo de existência, de existir. São convites que procuram proporcionar a possibilidade de uma relação e que, a cada vez, procuram estar atentos às respostas que lhe são dadas.

Essas respostas são muitas vezes corpóreas, e percebidas pelo nosso corpo, já que alguns participantes não têm o uso da linguagem verbal.

Os convites dão, então, lugar à recusa, o que nos leva a outro aspecto essencial do trabalho: a liberdade do sujeito em se inserir ou não numa proposta. Para nós, a liberdade em habitar o espaço de dentro ou o de fora de uma atividade deve ser privilegiada, pois não somente ela minimiza um poder existente como possibilita outras formas de estéticas.

O projeto é também um espaço de criação de vínculos sociais e fortalecimento da auto-estima, como podemos observar através do relato de J.A., uma das participantes do projeto que é estudante da UFMG e cadeirante. Ela nos 
diz: “... pude fazer amigos, desenvolver potenciais esquecidos ou pouco explorados que me ajudaram bastante a me reconhecer como pessoa e me tornar alguém melhor e mais capaz."

O Arte e Diferença é um espaço de formação para os estudantes. Para A.G., ele "tem um caráter importantíssimo não somente para pessoas em situação de deficiência como para os ditos normais. Ele agrega a arte de uma forma geral e a sua criação, além de nos transformar como seres humanos." D.O., bolsista desde o início do projeto, menciona que "na diversidade se deparou com outras formas de pensar, articular, dançar e fazer." Que o projeto trouxe para ela "muito mais do que imaginava, trouxe dúvidas e dificuldades, trouxe alegria e prazer, dor e beleza." Trouxe ainda "novas formas de estar, fazer e investigar." Jessica Luiza, estudante que participou no ano de 2017, relata que o projeto lhe

(...) permitiu enxergar a possibilidade de construção de um espaço, de um lugar onde a deficiência não seja meramente reduzida à incapacidade, mas de potência, abrindo possibilidades de criações e improvisações artísticas, estimulando a desenvolver novas ferramentas e a trabalhar com o imprevisto.

A estudante expressa, ainda, que nas oficinas encontrou "uma possibilidade de pensar em ferramentas metodológicas para o contexto escolar."

Todos os elementos já mencionados não só facilitam a implementação desta prática como são condicionadores da mesma. Dentre eles, ressaltamos a autoralidade, a articulação entre o singular e o coletivo, a liberdade do sujeito, o desapego de expectativas e a acessibilidade. Juntam-se a eles a qualidade da escuta, a capacidade de fazer silêncio, de disponibilidade, a observação curiosa, a humildade para aprender com o outro, a aceitação dos nossos próprios limites, dos limites do outro, do que nos é diferente, e o respeito.

Por tudo isso, o Arte e diferença é uma experiência que envolve uma conduta ética que exige uma atitude, um posicionamento, a escolha de uma certa abordagem de arte e educação, uma maneira de abraça-las, de praticá-las, de defende-las, de teoriza-las. Exige, sobretudo, um certo olhar sobre a diferença, 
sobre o inesperado, sobre o próprio conceito de normalidade. A.C.C. relata que com esta experiência vem aprendendo a ser "mais sensível e generosa" e a desenvolver práticas que "prezam a disponibilidade, a escuta, a atenção e o desejo."

Essa concepção de arte e educação, convoca e simboliza nossas ações como uma maneira de ser, como uma forma de ser/estar nesse mundo, com os outros. Este fazer é uma postura: coloca o corpo em uma qualidade que se abre para a poética da alteridade.

Consideramos que o sujeito no processo artístico e educacional não é um objeto da ação do outro, mas autor e criador do seu percurso, participando da construção do percurso dos outros, inclusive dos condutores das oficinas artísticas, do seu professor na rede escolar e dos demais atores da ambos os campos.

\section{Para concluir...}

Durante o período de implementação do projeto, verificamos resultados que vão sendo cotidianamente conquistados no processo de trabalho, e que dizem respeito aos efeitos das oficinas para os sujeitos participantes, para os oficineiros e para a articulação ensino-pesquisa-extensão.

Os participantes vão gradualmente incorporando a dinâmica de trabalho proposta, apropriando-se do espaço, da presença do outro, das sequências mais habituais, dos improvisos. Mantendo a poética de cada corpo em cena, os gestos singulares, olhares, aproximações e distanciamentos indicam a liberdade e a apropriação da escolha, a diminuição das barreiras iniciais e uma vivência mais espontânea de troca e interação com os outros, com o espaço e materiais utilizados.

Os oficineiros, estudantes que, muitas vezes, tiveram pouca oportunidade de experimentarem vivências com grupos mistos e de atuarem com pessoas que estabelecem formas de interação menos evidentes, têm sua capacidade de criação e de improvisação provocadas, e o desafio de desenvolverem 
metodologias de trabalhos mais adequadas às particularidades do grupo. Essa vivência tem efeitos relevantes para a formação profissional dos estudantes, despertando o senso crítico, a articulação teoria-prática e a implicação profissional voltada para um público diverso.

Nesse sentido, o projeto se articula diretamente ao ensino e à pesquisa universitária, pois permite a participação direta dos estudantes no planejamento e na execução das oficinas, abrindo toda uma possibilidade de pesquisa no campo da arte, da educação e da diferença.

Temos como desafio a transmissão da prática desenvolvida no projeto, por isso planeja-se a criação de um material didático-pedagógico. Pretende-se com isso, elencar ferramentas para auxiliar a implementação de oficinas artísticas para todos. Vale ressaltar que não buscamos criar receitas, mas, sim, compartilhar elementos fundantes de nossa prática, que possam ser apropriados e recriados por outros grupos.

Os seminários e congressos que temos organizado junto ao Grupo de Estudos e o Arte e Diferença nos fazem acreditar que muitos dos aspectos da nossa experiência podem ser de grande utilidade para profissionais de outros setores. Isso porquê propomos um espaço de criação, de forma artesanal. Como já dito, nosso fazer não é para o outro, mas com o outro. Por fim, ressaltamos a relevância da intersetorialidade que nos faz explorar diferentes perspectivas e novos fazeres a partir da riqueza da pluralidade do saber.

Recebido em 20/08/2019

Aceito em 10/10/2019

\section{Referências}

BORGES, Adriana A. P.; Campos, Regina Helena F. A Escolarização de Alunos com Deficiência em Minas Gerais: das Classes Especiais à Educação Inclusiva1. Revista Brasileira de Educação Especial, v. 24 (spe), p. 69-84, 2018.

DELIGNY, Ferdinand. CEuvres. Édition établie par Sandra Alvarez de Toledo. [S.I]. Paris: L’Arachnéen, 2007. 
FREIRE, Paulo. Pedagogia do Oprimido. Rio de Janeiro: Paz e Terra, 2005. FUX, María. Ser dança terapeuta hoje. São Paulo: Editora Summus, 2011.

GOFFMAN, Erving. Estigma: notas sobre a manipulação da identidade deteriorada. 4ª . Ed. Rio de Janeiro: Guanabara, 1988.

KASSAR, Mônica. C. M. Uma breve história educação das pessoas com deficiência no Brasil. In: Meletti, S. M F.; Escolarização de alunos com deficiências: desafios e possibilidades. Campinas (SP): Mercado das Letras, p. 33-76, 2013.

KLEIN, Jean Fraçois. Nous sommes tous des sang-mêlé: Ouvrage collectif. In: Le corps comme un lieu de métissages, Paris: L'Harmattan, p.367-386, 2003.

MAIOR, Isabel M. M. L.. Movimento político das pessoas com deficiência: reflexões sobre a conquista de direitos. Inclusão Social, v.10 (2), p. 28-36, 2017.

MEC. Indissociabilidade ensino-pesquisa-extensão e a flexibilização curricular: uma visão da extensão. Fórum de Pró-reitores de extensão das universidades públicas brasileiras. Porto Alegre: UFRGS; Brasil: MEC/SESu, 2006.

MERLEAU-PONTY, Maurice. O olho e o espírito. [S.I]. Rio de Janeiro: Editora Cosac Naify, 1984 (original de 1964).

RANCIÈRE, Jacques. Le maître ignorant. Paris: Collection Fait et cause - Édition Faillard, 1987.

SADER, Eder. Quando novos personagens entram em cena: experiências, falas e lutas dos trabalhadores da Grande São Paulo (1970-80). São Paulo: Paz e Terra, 1988.

TOLEDO, Sandra A. L'inactualité de Fernand Deligny. In: CEuvres. Édition établie par Sandra Alvarez de Toledo. [S.I]. Paris: L’Arachnéen, 2007, p.21-37.

PETTEN. Adriana M. V. N.; ROCHA, Terezinha C. C.; BORGES, Adriana A.P. (2018). Política de cotas na universidade federal de minas gerais: uma análise do perfil dos alunos com deficiência. Revista diálogos e perspectivas em educação especial, v. 5 (1), p. 127-140.

UFMG. Formações transversais/UFMG. Catálogo 2019.1. Belo Horizonte: UFMG, 2019.

UNESCO. Declaração de Salamanca e linha de ação sobre necessidades educativas especiais, 1994. 